\title{
A DOUBLE FACE VIEW ON MIND-BRAIN RELATIONSHIP: THE PROBLEM OF MENTAL CAUSATION ${ }^{1}$
}

\author{
Jonas Gonçalves Coelho ${ }^{2}$
}

\begin{abstract}
Interpreting results of contemporary neuroscientif studies, I present a non-reductive physicalist account of mind-brain relationship from which the criticism of unintelligibility ascribed to the notion of mental causation is considered. Assuming that a paradigmatic criticism addressed to the notion of mental causation is that presented by Jaegwon Kim's analysis on the theory of mind-body supervenience, I present his argument arguing that it encompasses a formulation of the problem of mental causation, which leads to difficulties by him pointed. To ask "how mental events, being a nonphysical property of the brain, could act causally on brain structure and functioning?", is not to treat the mind as a property of the brain, but as a Cartesian substance. I argue that, rather than asking "how does mind could act causally on the brain?", as if the mind were something apart and independent of the brain, it would be more in line with a non-reductive physicalist view to ask "how the brain, guided by its mind, could act causally on itself?". To justify this last formulation of the problem of mental causation, I propose a "double face view", which consists in considering the consciousness as the essential property of the mind, and mind and brain as inseparable, dependent and irreducible faces. It means, in general terms, that the conscious mind is the result of brain structure and activity - "conscious mind as brain" - and that the brain, using its conscious mind as a guide to its actions, interacts with its body, and with the physical and sociocultural environment, constructing and being constructed by both - "brain as conscious mind".
\end{abstract}

Keywords: Double face view. Conscious mind. Mental causation. Mind-brain relationship. Supervenience. Jaegwon Kim.

\section{INTRODUCTION}

In what follows I present a double face view of mind-brain relationship, from which I will face the criticism of unintelligibility ascribed to the notion of mental causation. I assume that "mind" and "brain" are essentially distinct, a distinction established in terms of oppositions such as material/immaterial, physical/non-physical, objective/subjective and quantitative/qualitative. However, this assumption does not imply a Cartesian view according to which

\footnotetext{
${ }_{1}$ This paper results from a research developed from December, 2014 to November, 2015, which was sponsered by FAPESP.

${ }^{2}$ Human Science Department and Philosophy Postgraduation Program, University of Sao Paulo State. E-mail: jonas@faac.unesp.br
}

http://dx.doi.org/10.1590/S0101-31732017000300011 
"mind" and "brain" are two substances ${ }^{3}$, which, although connected, could exist separately and independently, after all, it does not seem reasonable to infer, from the Cartesian distinction between mind and body, the existence of an immaterial substance: the "soul". As it is widely known, this Cartesian inferential mistake led to the paradigmatic version of the mind-body problem, which consists in explaining how an immaterial substance could be connected to a material substance and how they could interact causally. These difficulties and the subsequent scientific development, particularly of evolutionary biology and neuroscience, took some philosophers to postulate that the immaterial or non-physical mind is not a substance, neither a soul nor the brain itself, but a resultant property of the physical, so arguing for a non-reductive physicalist approach of the mind-physical relationship defined in the following terms:

Non-reductive physicalism is characterized by (at least) the following two theses: Distinctness: Mental properties are distinct from physical properties. Dependence: Mental properties are properties of physical objects. Non-reductive physicalism can therefore be distinguished from the property or 'type' identity theory on the one hand, and Cartesian dualism on the other. The identity theory asserts that mental properties are identical with physical properties, which is the denial of Distinctness; and Cartesian dualism asserts that mental properties are properties of mental substances, which is one way of denying Dependence. The commitment to Dependence is what makes non-reductive physicalism physicalist, and the commitment to Distinctness is what makes it non-reductive. (CRAINE, 2001 , p. 2). ${ }^{4}$

Several contemporary philosophical views reject this new form of dualism, denying the existence of an immaterial or non-physical mind, be

\footnotetext{
${ }^{3}$ In the book Principles of Philosophy, Descartes defines substance as something that not dependent on another thing to exist, i.e., rather, it serves as a substrate or support to other existing beings who would be its attributes. It is in this sense that the philosopher says in Article 51: "[...] a substance is a thing that exists in such a way that it does not depend on anything else for its existence." And immediately after, in the Article 52, reiterates the same position, only adding that the substance is a divine creation that does not depend on another divine creation: "[...] things that do not depend for their existence on anything except God.” (DESCARTES, 1952, p. 594).

${ }^{4}$ I prefer to use the term "physicalism" instead of "materialism" because it is not clear in what sense physical forces such as gravity or electromagnetism could be considered as material entities, although many physicalist philosophers use the words "physicalism" and "materialism" interchangeably. By saying that human beings are physical entities, I mean that they are constituted by entities of the kind posited in physics, chemistry and biology. So, I consider the brain as a physical-chemical-biological system that interacts with the body in which it is located and with the physical and socio-cultural environment in which it is situated.
} 
reducing the mind to behavior (SKYNNER, 1974) and/or replacing the mental language for a behavioral language (RYLE, 1949), be identifying and reduce the mind to the brain (SMART, 1950; PLACE, 1956), be eliminating the mind or mental language from the scientific language (CHURCHLAND, 1981). Assuming that one of the main reasons for this sort of rejection of any non-reductive physicalist view is the difficulty of explaining how the mind could act causally on the brain, I will focus on this problem, leaving aside the huge debate about both, the distinction between the mind and the physical and the physical as the cause of the mind.

An essential point to be firstly clarified is the definition of mind. I will assume, in agreement with John Searle, that consciousness is the essential property of the mind, the "central mental notion" (SEARLE, 1992, p. 83), and that, although difficult to define, everyone knows to some extent what we are talking about: "Consciousness is an on/off switch: a system is conscious or not. But once conscious, the system is a rheostat: there are different degrees of consciousness." (SEARLE, 1992, p. 83) According to this philosopher, the conscious states always have content: someone is conscious of something. (SEARLE, 1992, p. 83) So, we can ask "what is it like to be an individual $A$ ", to paraphrase Thomas Nagel (2008) in his article "What is it like to be a bat?", if we want to know how is the subjective experience or phenomenal consciousness of the individual $A$. For example, we can ask how is it to feel thirsty, to feel sad, to feel guilt, to see a red apple, to pay attention in a dangerous animal, to live or to remember a scared experience, to think about the future of our career, to reasoning to win a chess game, to calculate to solve an equation, to have concepts such as color, time and black hole, to believe in God, to have the intention to get married, etc. I follow Ned Block (1995, p. 211) when he says:

I used as synonyms 'subjective experience' and 'what it is like to be us'. In explaining phenomenal consciousness, one can also appeal to conscious properties or qualities, e.g. the ways things seem to us or immediate phenomenological qualities. Or one can appeal to examples: the ways things look or sound, the way pain feels and more generally the experiential properties of sensations, feelings and perceptual experiences. I would also add that thoughts, wants and emotions often have characteristic conscious aspects, and that a difference in representational content can make a phenomenal difference. Seeing something as a cloud differs from seeing it as a part of a painted backdrop. What it is like to hear Bulgarian spoken depends on whether on understands the language. ${ }^{5}$

${ }^{5}$ A wide "catalog of conscious experiences" can be found, for example, in the first chapter of the book

"The Conscious Mind: In Search of a Fundamental Theory" by David Chalmers. 
If it is accepted that consciousness, such as considered above, is the essential property of the mind ${ }^{6}$, the big questions or hard problems on mindbody relationship would be "if and how the brain could create a conscious mind", and "if and how a conscious mind could act causally on the brain". As I said before, this paper will be mainly focused on the last problem, i.e., the problem of mental causation. To face it, I will propose a "double face view" according to which conscious mind and brain are two inseparable, dependent and irreducible faces of human beings. It means that, on the one hand, that the existence, form and content of the conscious mind is a result of the structure and functioning of the physical brain, embodied and situated physically and socioculturally. On the other hand, that the structure and functioning of the brain, besides being a physical/biological construction, is also, thanks to its conscious mind, a product of the physical and sociocultural environment in which the brain is embodied and situated. In short, I propose an approach of the mind-brain relationship according to which the brain, physically embodied and situated, is the organ of the embodied and situated conscious mind, and the conscious mind is a resultant property of the embodied and situated brain, which enables the brain (brains) to construct and to interact with the physical and sociocultural environment.

From this double face view on mind-brain relationship I will face the ascription of unintelligibility addressed to the notion of mental causation. Considering that one paradigmatic criticism of the notion of mental causation, such as understood by any non-reductive physicalism view, is that offered by Jaegwon Kim in his remarks on the theory of mind-body supervenience ${ }^{7}$, I will start presenting, in general terms, his arguments.

${ }^{6}$ From now on I will use the expression "conscious mind" not intending to reduce the mind to consciousness, but just to focus on the problem of consciousness considering it, as I told before, as the main property of the mind, or, at least the property responsible for the most difficult philosophical problems.

7 The Kim criticism of mental causation encompasses physicalism in general, whose essential features would be gathered in the theory of mind-body supervenience: “ $\ldots$ our considerations indicate that mind-body supervenience captures a commitment common to all positions on the nature of mentality that are basically physicalistic. For it represents the idea that mentality is at bottom physically based, and that there is no free-floating mentality unanchored in the physical nature of objects and events in which it is manifested. This is an idea that can be shared by many diverse positions on the mindbody problem, from reductive type physicalism at one extreme to dualistic emergentism at the other. In contrast, mind-body supervenience is inconsistent with more extreme forms of dualism, such as, Cartesian dualism, which allow the mental world to float freely, unconstrained by the physical domain. Thus, mind-body supervenience can serve as a useful dividing line: it can be viewed as defining minimal physicalism. (KIM, 1998, p. 14-15). 


\title{
SUPERVENIENCE AND THE DILEMMA OF MENTAL CAUSATION
}

Jaegwon Kim presents his definition of mind-body supervenience following the proposal of Donald Davidson in the book "Mental Events". According to Kim, "Mental properties supervenes on physical properties in the sense that if something instantiates any mental property $M$ at $t$, there is a physical base property $P$ such that the thing has $P$ at $t$, and necessarily anything with $P$ at a time has $M$ at that time. ${ }^{8}$ (KIM, 1998, p. 39). According to Kim, interpreting Davidson, there is a necessary relationship between the type of mental event and the type of physical event, which should be understood in nomological terms, what means that it applies only to worlds with the same laws. From this, we could infer that if one individual, while experiencing a mental event, had an identical biological copy, it would be impossible for this copy to be a zombie, that is, a mindless being, after all, the existence of the same laws and specific physical events would be necessary and sufficient for the instantiation of related mental events.

\begin{abstract}
Mind-body supervenience grounds each mental phenomenon in the physical domain by providing for it a set of physical conditions that are (at least) nomologically sufficient for it and on which its occurrence depends. A corollary is the thesis that no mental phenomenon can occur, and no mental property can be instantiated, unless an appropriate physical base condition is present. Every mental event, be it a sensation like pain or itch, or an intentional state like belief and desire, must have a physical basis: it occurs because an appropriate physical basis is present, and it would not occur if such a basis was absent. (KIM, 1998, p. 40).
\end{abstract}

It means that Davidson's supervenience is an asymmetric view according to which, on the one hand, the mind depends on the body or the body determines the mind: "[...] if the mental supervenes on the physical, the mental is dependent on the physical, or the physical determines the mental, roughly in the sense that the mental nature of a thing is entirely fixed by its physical nature." (KIM, 1998, p. 11) On the other hand, the opposite does not apply, that is, the body does not depend on the mind, and the mind does not determine the body.

\footnotetext{
${ }^{8}$ The same text presents two other slightly different definitions of mind-body supervenience: "Mental properties supervene on physical properties, in that necessarily, for any mental property $M$, if anything has $M$ at time $t$, there exists a physical base (or subvenient) property $P$ such that it has $P$ at $t$, and necessarily anything that has $P$ at a time has $M$ at that time." (KIM, p. 9) "Mental properties supervene on physical properties, in that necessarily any two things (in the same or different possible worlds) indiscernible in all physical properties are indiscernible in mental aspects." (KIM, 1998, p. 10).
} 
The relation of dependence, or determination, is asymmetric: if $x$ depends on, or is determined by $y$, it cannot be that $y$ in turn depends on or is determined by $x[\ldots]$ We will simply follow the customary usage and understand supervenience to incorporate a dependence/determination component as well. In fact common expressions like 'supervenience base' and 'base property' all but explicitly suggest asymmetric dependence. (KIM, 1998, p. 11).

According to Kim, Davidson assumes, without explaining it, that this relation of dependence/determination between mind and body is not an explanation of the mind-body relationship, but only a statement of "[...] 'phenomenological' relation about patterns of property covariation, patterns that possibly are manifestations of some deeper dependence relationships." (KIM, 1998, p. 14). So, Kim concludes that the "[...] mind-body supervenience states the mind-body problem - it is not a solution to it." (KIM, 1998, p. 14). ${ }^{9}$ Considering the supervenience as a view common to different non-reductive physicalist approaches of the mind-brain relationship (cf. note 3), Kim is not concerned about if and how the brain causes the mind, being mainly interested in the problem of mental causation, that is, the causal action of the mind on the brain.

Kim argues that the notion of mental causation is unintelligible. To demonstrate that, the philosopher considers the case of a mental event $M$ causing another mental event $M^{*}$, i.e., "a case of mental-to-mental causation, one in which an instance of a mental property causes an instance of another mental property.” (KIM, 1998, p. 41) To follow Kim's argument we could think in examples such as "the feeling of headache $(\mathrm{M})$ causing the decision

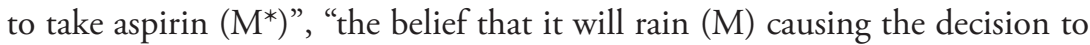

\footnotetext{
${ }^{9}$ Hold that mind and body keep a dependency relationship does not mean explain this relationship, and the Davidson theory of mind-body supervenience is not, according to Kim, an "explanatory theory" of the mind-body relationship, being consistent with many incompatible approaches of this theme, such as the emergentism, the physical realizationism or physicalist functionalism, the epiphenomenalism and the identity theory: "If mind-body supervenience is a commitment of each of these diverse and conflicting approaches to the mind-body problem, it cannot itself be a position on this problem that can be set alongside these classic alternatives." (KIM, 1998, p.12). According to Kim, the " $[\ldots]$ supervenience is silent on the nature of the dependence relation that might explain why the mental supervenes on the physical $[\ldots]$ supervenience is not a type of dependence relation - it is not a relation that can be placed alongside causal dependence, reductive dependence, mereological dependence, dependence grounded in definability or entailment, and the like. Rather, any of these dependence relations can generate the required covariation of properties and thereby qualify as a supervenience relation." (KIM, 1998, p. 14).
} 
take an umbrella $\left(M^{*}\right)$ " and "the intention to go to the theater $(M)$ causing the decision to buy tickets $\left(\mathrm{M}^{*}\right)$." I will reconstruct Kim's criticism of the non-reductive physicalist notion of mental causation using only one of the mentioned examples, the mental event "feeling of headache" (M) causing the mental event "decision to take aspirin" $\left(\mathrm{M}^{*}\right)$.

Kim initiates his argumentation saying that, according to mindbody supervenience, the mental event $M^{*}$ ("decision to take aspirin") has a physical basis ("brains process*") $P^{*}$. So the question is: was the mental event $M^{*}$ ("decision to take aspirin") instantiated because the mental event $M$ ("feeling of headache") was instantiated, or because the physical event ("brain process*”) $P^{*}$ was instantiated? According to mind-body supervenience, the instantiation of the mental event $M^{*}$ ("decision to take aspirin") depends on the instantiation of its physical base ("brain process*") $P^{*}$, regardless of what has previously occurred. Under this perspective, Kim argues, how could the notion of mental causation make sense? To assume that the mental event $M$ ("feeling of headache") does not directly cause the mental event $M^{*}$ ("decision to take aspirin"), but the intermediate physical event ("brain process*") $P^{*}$, is to accept that a mental event could cause a physical event.

Kim argues against this alternative explanation. First, it would apply to mental event $M$ ("feeling of headache"), the same principle applied to mental event $M^{*}$ ("decision to take aspirin"), that is, the mental event $M$ ("feeling of headache") has to have a physical basis ("brain process") $P$ without which it would not exist. However, what would be responsible for the physical event ("brain process*") $P^{*}$, the mental event $M$ ("feeling of headache"), the physical event ("brain process") $P$, or both acting together? Kim privileges the physical event ("brain process") $P$ against the mental event $M$ ("feeling of headache) as cause of ("brain process") $P^{*}$, considering the notion of cause both, in terms of nomological sufficiency and counterfactuals. The nomological sufficiency formulation: because the physical event ("brain process") $P$ is sufficient for the mental event $M$ ("feeling of headache") and the mental event $M$ ("feeling of headache") is sufficient for the physical event ("brain process*") $P^{*}$, ("brain process") $P$ is sufficient to ("brain process*") $\mathrm{P}^{*}$. The counterfactual formulation: if the physical event ("brain process") $P$ had not occurred, the mental event $M$ ("feeling of headache") also would not have occurred, and given that if the mental event $M$ ("feeling of headache") had not occurred, ("brain process*") $P^{*}$ would not have occurred, it follows that if the physical event ("brain 
process") $P$ had not occurred, the physical event ("brain process*”) $P^{*}$ also would not have occurred (KIM, 1998, p. 43).

Besides the dependence of the physical above mentioned, mental causation would bring out another problem, the "overabundance of causes" or "causal overdetermination", since both, the mental event $M$ ("feeling of headache ") and the physical event ("brain process") $P$ provide "sufficient causes of $P^{* *}{ }^{10}$ Kim thinks that it is unreasonable to consider the mental event $M$ ("feeling of headache") and the physical event ("brain process") $P$ as constituting together a unique cause of ("brain process*”) $P^{*}$, since each one would be enough to cause ("brain process*") $P^{*}$, therefore, not being clear what the other one could add in causal terms. In addition, to consider the mental event $M$ ("feeling of headache") as necessary for the causation of the physical event ("brain process*”) $P^{*}$, would be a violation of the principle of causal closure of the physical world. Finally, a physical cause could replace a mental cause, rendering the latter unnecessary: "If you pick any physical event and trace out its causal ancestry or posterity, it never will take you outside of the physical domain. That is, no causal chain will ever cross the boundary between the physical and the nonphysical." (KIM, 1998, p. 40).

It means that "the feeling of headache", "the belief that it will rain", "the intention to go to the theater", examples of mental events mentioned before, could not be considered as causes of physical events ("brain process") that would sustain other mental events such as "the decision to take aspirin", "the decision to take an umbrella" and "the decision to buy tickets", respectively. If considered as a property of the brain outside of the physical domain, the mind could not act causally on the physical ("brain process"): “[...] the physical determines the mental, and in that sense the mental does not constitute an

\footnotetext{
${ }^{10}$ The problem, according to Kim, is "[...] the existence of two causal claims, each purporting to provide a sufficient cause of a single effect" (KIM, 1998, p. 65), as illustrated by the following example: "Suppose then that my desire for water causes a certain motion of my body. This is a case of mental-tophysical causation. So far so good. But metaphysical problems begin to emerge in several ways. First, suppose that we trace the causal chain back from my bodily motion - to simplify, the movement of my left foot as I take my first step toward the kitchen. I assume we have a pretty good neurophysiological story to tell about how such limb motion occurs, a story involving transmission of neural signals, contraction of a group of muscles, and so on; let us suppose that the story ends with some neural event in my central nervous system, presumably the firing of a group of neural fibers somewhere deep in the brain. There seems every reason to think that such a neurophysiological causal explanation also exists; at least, we cannot rule out such a possibility. What then is the relationship between this explanation and the intentional explanation in terms of my foot movement? One invokes a neural state, $\mathrm{N}$, as cause of my foot movement; the other invokes my desire for a drink of water, as a cause of the very same event. How are these two causes related to each other?" (KIM, 1998, p. 64).
} 
ontologically independent domain that injects causal influences in to the physical domain from the outside." (KIM, 1998, p. 41).

Being the notion of mental causation incompatible with mind-body supervenience, the causal relationship present at the physical level (" $P$ causes $\left.P^{* \prime)}\right)$ would not exist neither at the mental level (" $M-M^{* \prime)}$ nor from the mental to physical (" $M-P^{*}$ "). The regularity observed between $M$ and $M^{*}$ ("feeling of headache" and "decision to take aspirin") and between $M$ and $P^{*}$ ("feeling of headache" and "brain process*") would not be a causal regularity, but a regularity dependent on the only existing causal regularity, that is, ("brain process) $P$ causing ("brain process $\left.{ }^{*}\right) P^{*}$. An analogy proposed by Kim clarifies his conclusion. The situation would be "[...] like a series of shadows cast by a moving car: there is no causal connection between the shadow of the car at one instant and its shadow an instant later, each being an effect of the moving car." (KIM, 1998, p. 45). It means that the " $M$-to- $M^{*}$ ("feeling of headache" and "decision to take aspirin") and $M$-to- $P^{*}$ ("feeling of headache" and "brain process*") causal relations are only apparent, arising out of a genuine causal process from $P$ to $P^{*}$." (KIM, 1998, p. 45) Kim concludes that mental causation is unintelligible, whether the mind-body supervenience fails or succeeds: "If the mind-body supervenience fails, mental causation is unintelligible; if it holds, mental causation is again unintelligible. Hence, mental causation is unintelligible." (KIM, 1998, p. 46).

\section{FACING THE DILEMMA OF MENTAL CAUSATION}

Although Kim has constructed his argument considering the mental causation of a mental event ("feeling of headache" causing the "decision to take aspirin"), the hard problem, which led him to privilege the physical event $P$ as the cause of the physical event $P^{*}$, is the supposed mental causation of a physical event, that is, to explain how a mental event $M$ ("feeling of headache") could, by itself, cause a physical event $P^{*}$ ("brain process") that would support a mental event $M^{*}$ ("decision to take aspirin"). As the neuroscientist Michael Gazzaniga (2011, p. 240) says:

The classic puzzle is usually put this way: There is a physical state, $\mathrm{P} 1$, at time 1 , which produces a mental state, M1. Then after a bit of time, now time 2, there is another physical state, $\mathrm{P} 2$, which produces another mental state, M2. How do we get from M1 to M2? This is the conundrum. We know that mental states are produced from processes in the brain so that M1 does not directly generate M2 without involving the brain. If we just 
go from P1 to P2 then to M2, then our mental life is doing no work and we are truly just along for the ride. No one really likes that notion. The tough question is, does M1, in some downward-constraining process, guide $\mathrm{P} 2$, thus affecting $\mathrm{M} 2$ ?

As I will argue in the third part of this section, this kind of formulation of the problem of mental causation, "how the mind, being an non-physical property of the brain, could act causally on the brain?", induces us to conceive the mind as if it were an non-physical substance, and not a non-physical property of the brain, although that is not what non-reductive physicalists, as the proponents of supervenience theory, think. To ask "how the feeling of headach, being a mental event, could cause the brain events that are subvenient to the decision to take aspirin?" is to think about the feeling of headach as if it were an non-physical autonomous cause of brain events and not a nonphysical property of a brain, which, by experiencing that feeling, decides to take aspirin. As John Searle says: "[...] it is as if the mind sprang up from the behavior of neurons and, after that, it had a life of its own." (SEARLE, 1992, p. 163).

Assuming that the problem of mental causation, such as formulated before, stems from treating the mind as if it were a Cartesian substance, and not a property of the brain, I believe that it would be possible to solve that problem interpreting the notion of mental causation in accordance with the non-reductive physicalist view of mind-brain relationship, which I present, in general terms, in the following. Interpreting results of Neuroscience research, I propose a "double face view" of mind-brain relationship according to which the two faces of the mind-brain relationship are essentially distinct, inseparable and irreducible, one requiring and founding the other. First, I consider the conscious mind as brain (conscious mind $\rightarrow$ brain), with which I mean that the structural and functional organization of the brain is the cause not just of the existence, but also of the properties - form and content - of the conscious mind. Second, I consider the brain as conscious mind (brain $\rightarrow$ conscious mind), meaning that the conscious mind is a cause of the structural and functional organization of the brain. As I will argue, this approach of the problem of brain-conscious mind and conscious mind-brain relationship does not imply an undervaluation of the body and of the physical and sociocultural environment in which the conscious brain is embodied and situated. 


\section{Conscious Mind As Brain}

The thesis that the structural and functional organization of the brain is the immediate cause ${ }^{11}$ of existence, form and content of the conscious mind - conscious mind as brain - has been endorsed by evolutionary biology and by neuroscientific research. Roughly speaking, the evolutionary biology allows us to state that the emergence of the conscious mind is relatively recent in the history of the universe, getting in to existence only and when and where the matter acquired, by genetic inheritance and natural selection, a particular kind of organization, a nervous system with a specific level of complexity. The neoDarwinism version of evolutionary biology also allows us to postulate that the conscious mind is not a fundamental entity, independent and separate from the physical world, but a specific phenotype, i.e. an adaptive property of the living matter, through which this acquired, in its interaction with other physical and biological structures, specific levels of complexity.

The assumption that the brain is the immediate cause of the conscious mind has also been supported by countless neuroscientific studies, most of them published in the last 30 years, which use different methods of research and technologies that allow peer the normal and abnormal brain during and after cognitive, affective and behavioral tasks. This sort of research has fostered the development of therapeutic practices targeting cognitive, affective and behavioral dysfunctions, by manipulating the brain, for example, chemically and electromagnetically, changing its structure and functioning on both levels, macrophysical and microphysical. Pointing to the same direction, there is a wide research program, which include: studies of brain injuries and its implications to emotional, cognitive and moral process behavior; brainmachine interface; cranial electromagnetic stimulation; development of drugs for mental illness, emotional states (schizophrenia, depression, anxiety, etc.), cognitive optimization and moral (Ritalin, serotonin, oxytone, etc.). As the neurophilosopher Patricia Churchland says in her recent book "Touching a Nerve: the self as brain":

Evidence did accumulate from many different directions. For example, physical changes in the brain produced changes in supposedly soul functions, such as consciousness, thought, and reasoning. Inhaling as anesthetic such as ether caused people to lose consciousness; ingesting a substance such as mescaline or peyote cause people to experience vivid

\footnotetext{
${ }^{11}$ As I will argue soon, to consider the brain as the immediate cause of the conscious mind does not mean to disregard its mediate causes such as the body and the physical and sociocultural environment without which the brain would not exist and would not be structurally and functionally what it is.
} 
hallucinations. Neurologists reported very specific losses of function correlated with damage to a very specific place in the cortex (the fusiform) will likely lose the capacity to recognize a familiar face; a stroke in a somewhat different area will cause the loss of the ability to understand speech. Loss of social inhibition may follow a stroke that destroys the prefrontal cortex just behind the forehead. All these phenomena seem to point to the nervous system, not to nonphysical, spooky stuff. (CHURCHLAND, 2013, p. 49).

I think that there is sufficient evidence to assume that the conscious mind is a property of the brain, embodied and situated physically and socioculturally. Differently from contemporary philosophers of mind, such as Thomas Nagel and David Chalmers, who consider mysterious this relationship, I believe that this is a difficult problem, but not a mystery, if mystery is understood as a problem by principle insoluble. To solve this problem would consist in understand the structure and functioning of the brain associated to conscious mind events and states. It does not seem necessary to go further in science, not making sense to ask why such structure and functioning cause the conscious mind or why a specific functioning of the brain produces an specific mental event and not another. I do agree with David Chalmers, when, paradoxically, he says:

There is a system of laws that ensures that a given physical configuration will be accompanied by a given experience, just as there are laws that dictate that a given physical object will gravitationally affect others in a certain way.

It might be objected that this does not tell us what the connection is, or how a physical configuration gives rise to experience. But the search for such a connection is misguided. Even with fundamental physical laws, we cannot find a "connection" that does the work. Things simply happen in accordance with the law; beyond a certain point, there is no asking "how". As Hume showed, the quest for such ultimate connections is fruitless. If there are indeed such connections, they are entirely mysterious in both the physical and psychological cases, so the latter poses no special problem here.

It is notable that Newton's opponents made a similar objection to his theory of gravitation: How does one body exert a force on another far away? But the force of the question dissolved over time. We have learned to live with taking certain things as fundamental. (CHALMERS,1996, p. 170). 
Thus, considering the current way in which science explains natural phenomena, that is, accepting that the scientific explanation of one phenomenon generally consists in identifying the correlated phenomenon that precede and/or accompany it regularly in time, there would be no exaggeration or privilege of the psychophysical relationship. Either this current mode of scientific procedure is legitimate, and therefore also appropriate to the psychophysical relationship, or it also involves mystery, which would not be then a privilege of the conscious mind-brain relationship. I think that, on both cases, one face a difficult problem, but not a mistery.

\section{Brain As Conscious Mind}

According to the other face of mind-brain relationship - brain as conscious mind - the brain dependence on conscious mind is also supported by contemporary research in neuroscience, from which it can be inferred that the brain, besides being physically embodied and situated, is also mentally embodied and situated. It means that, via conscious mind, though not exclusively, the brain interacts with its body and with the physical and the socio-cultural environment in which it is immersed. The sense organs and proprioceptive/interoceptive structures of the body can be considered as a kind of window that allows the brain, that is inside of the head, to interact with the body, in which it is located, and with the physical and sociocultural environment, in which it is situated, being it the consciousness - the essential property of the mind - one specific property of the brain, which is present in all of that windows. It is known that the brain interacts unconsciously with physical stimuli through the sense organs and proprioceptive/interoceptive mechanisms, but what I am particularly interested in is the ability of the brain to interact via consciousness with both, the physical and the socio-cultural environment. What the brain is and what the brain makes is inseparable from its structural and functional architecture, genetically constructed and, as studies of brain plasticity show, resultant of brain interactions with the physical and sociocultural environment. ${ }^{12}$

\footnotetext{
${ }^{12}$ In line with recent neuroscientific and psychological research, I just sketch a general conception of the mind-brain relationship, with which I will face the problem of mental causation. Thus, the scheme of the mind-brain relationship presented here should be seen as a general design based on the current state of scientific knowledge, as exemplified by Joseph LeDoux in his book "Synaptic Self", when he talks about the relationship among self (which I consider a particular kind of conscious mind), brain and environment: "The self can be understood in terms of brain systems involved in learning and storing information, in explicit and implicit systems, about things that are significant in people's
} 
So, the structure and functionality of the brain depends on preinstalled cognitive and emotional capabilities built genetically, and on physical/ sociocultural environment, which affects the brain thanks to its ability to interact with the external world via its conscious mind. Regarding this aspect, the contemporary neuroscience has shown that the brain is not only modified when it is physically altered by sensory stimuli, by injury, surgery, chemical and electromagnetic manipulation, etc., but also, thanks to its plasticity, by many different kinds of physical and psychological experiences. As shows a paradigmatic definition of brain plasticity, there is an essential relationship between brain changes and experience: "[...] we can define brain plasticity as the capacity of neurons and of neural circuits in the brain to change, structurally and functionally, in response to experience." (SALE; NICOLETTA; MAFFEI, 2014, p. 190). As Joseph LeDoux says about the relationship among genetics, learning, memory and brain plasticity:

\begin{abstract}
Most systems of the brain are plastic, that is, modifiable by experience, which means that the synapses involved are changed by experience... An innate capacity for synapses to record and store information is what allows systems to encode experiences. If the synapses of a particular brain system cannot change, this system will not have the ability to be modified by experience and to maintain the modified state. As a result, the organism will not be able to learn and remember through the functioning of that system. All learning, in other words, depends on the operation of genetically programmed capacities to learn. Learning involves the nurturing of nature. (LEDOUX 2002, p. 8).
\end{abstract}

What neuroscientists in general do not specify, but I am considering as fundamental, is that what is said about experience can be interpreted, at least in many cases, as conscious experience. So, I am here specially thinking about the relationship between conscious experiences and brain plasticity and assuming that, by exposure to sociocultural practices, such as those related to a regular education, a child, by mean of its conscious mind, has its brain

lives. The processing by these systems always occurs in a physical and social context (a situation) and is performed by networks that function the way they do because of both genetic inheritance and past experiences. Put this way, in order to understand the self, we need to explain how brain systems underlying thinking, emotion, and motivation (the mental trilogy) develop under the influence of nature and nurture, and how these systems make it possible for us to attend to, perceive, learn about, and store and retrieve experiences. We especially need to explain how different systems interact with and influence one another. Without these interactions, and the mental integration they engender, each of us would simply be a collection of isolated mental functions rather than a coherent person." (LEDOUX, 2002, p. 32). 
modified, that is, the sociocultural learning is not an abstraction, apart from what happens in the brain. I think this view implies the reformulation of the problem of mental causation, as I will try to show in the next section.

\section{Reformulating The Problem Of Mental Causation}

Retaking the problem of mental causation, I think that the outlined non-reductive physicalist "double face view" on mind-brain relationship requires a non-Cartesian formulation of the question, different from that assumed by Kim. Rather than asking, "how the mind, being a non-physical property of the brain, could act causally on the brain?", it should be asked, "how the brain, guided by its conscious mind, acts causally on the brain?". Instead of treating the mind as a non-physical substance, which, by itself, would have a causal power on the physical brain, as implied by the first formulation of the question, the conscious mind should be seen as a nonphysical property of the brain, by means of which the brain acts upon itself. ${ }^{13}$ What I am proposing here is to focus on the causal power of the brain derived from the fact that it has a conscious mind, which implies, as it was said before, to understand how the fact of having a conscious mind determines the structure and functionality of the brain. Let us suppose, for example, that one says that the weight of a rod of iron caused the fracture of a person's spine. It does not mean that the weight by itself caused the fracture, which would be puzzling, since the weight, although resultant of gravitational acceleration, would not exist without a mass. This allows us to say that, at least in some measure, the weight depends on the ratio of the mass of the iron rod and the physical environment (gravitational force) in which the iron rod is situated. Thus, it would be more appropriate to say that it is not the weight by itself, but the iron rod that, thanks to its weight, caused the fracture of the spine. ${ }^{14}$

\footnotetext{
${ }^{13}$ The way a brain state influences another brain state has been the subject of research in neuroscience whose most commonly cited example has been the description of the sequence of events in sensorymotor brain. But that is a small part of a broad program of research in neuroscience, which has a long way ahead given the complexity of the correlation between brain processes and mental phenomena. This aspect is pointed by Joseph LeDoux (2002, p. 319): "If a thought is embodied as a patterns of synaptic transmission within a network of brain cells, as must be the case, then it stands to reason that the brain activity that is a thought can influence activity in other brain systems involved in perception, motivation, movement, and the like. But there's one more connection to make. If a thought is a pattern of neural activity in a network, not only can it cause another network to be active, it can also cause another network to change, to be plastic."

${ }_{14}$ The example presented aims just to clarify the view proposed. It does not arrogate to be a precise and complete description of the scientific explanation of weight.
} 
It follows from what it was just said that explanatory practices mentioned in previous sessions, such as, for example, "I took aspirin because I had a headache", based on counterfactuals like "I would not have taken an aspirin if I did not get a headache", could be compatible with brain events without the need of thinking neither that the "feeling of headache", by itself, caused the brains events that are subvenient to the "decision to take aspirin", nor that the brain caused at the same time the "feeling of headache" and the "decision to take aspirin", as if there were no causal relationship between the "feeling of headache" and the "decision to take aspirin". Rather, it could be said something like this: "because the brain felt headache, the brain decided to take aspirin" and "if the brain did not feel headache it would not (keeping the other conditions the same) have decided to take aspirin".

Therefore, to accept that the brain plays an essential causal role, being causally responsible by mental and brain/body events, does not imply the exclusion of the causal power of the conscious mind, that is, it does not render the conscious mind in a mere epiphenomenon or shadow of the brain. Even if we consider that the contents of consciousness depend on the relationship among brain, body and external physical and sociocultural environment - some sort of externalist approach to the mind -, that do not prevent the conscious contents of being a result of brain structure and functioning. I am assuming that the embodied and situated brain is the organ of the conscious mind and that the conscious mind gives the brain causal powers which the latter would not have without the former. So it is legitimate to ascribe a causal power to conscious mind, as it is justifiable to attribute a causal power to the physical and sociocultural environment, which, by changing the brain, offer the most part of the contents its conscious mind.

\section{Against the EpiphenomenisM}

Let me talk a little bit more about the causal role of the conscious mind in a physical world. I will do it critisizing the epiphenomenalism, taking as a guide its paradigmatic defense presented by Frank Jackson in the latter part of his text "Epiphenomenal Qualia", which became famous for the proposal and interpretation of a thought experiment known as "the neuroscientist Mary." Frank Jackson defends an epiphenomenal property dualism whereby the qualia, defined as a non-physical property "of certain mental states" of the brain, are "causally impotent with respect to the physical world", that is, "[...] they 
are such that their possession or absence makes no difference to the physical world." (JACKSON, 2002, p. 276). To defend the epiphenomenalism, the philosopher proposes to refute three arguments in favor of the causal power of qualia, taking as an example what he thinks to be the supposed causal power of pain, that is, criticizing the idea widely accepted "[...] that the hurtfulness of pain is partly responsible for the subject seeking to avoid pain [...] that a quale like the hurtfulness of a pain must be causally efficacious in the physical world, and so, for instance, that its instantiation must sometimes make a difference to what happens in the brain." (JACKSON, 2002, p. 276).

I start considering Jackson's first argument for epiphenomenalism, that is, against the causal power of the conscious experience of pain. Quoting the empiricist philosopher of the eighteenth century David Hume, Jackson says that the "seeking to avoid pain" following the "hurtfulness of a pain" does not prove that the "hurtfulness of a pain" caused the behavior of "seeking to avoid a pain", after all, both could be explained "by an overarching theory" that could show "the two as distinct effects of a common underlying causal process", for example, that they are "[...] simply a consequence of the fact that certain happenings in the brain cause both.” (JACKSON, 2002, p. 276-277).

Using the same argument I hold that Jackson could not defend, as he does, that mental events are a property of the brain, for he concludes that based on the same kind of regularity between brain events and mental events, the later following the former. But Jackson should in this case use the same reasoning assuming that both, the brain and mental events could be the effect of an underlying unknown cause, for example, laws still unknown and/or of a direct divine action on both events producing some kind of psychophysical parallelism, without any kind of direct relationship between physical and mental events. Why should Hume's argument be accepted against the causal power of the conscious mind on the brain and not against the causal power of the brain on the conscious mind?

The second Jackson's argument against the causal power of conscious mind (qualia) is suggested by Darwin's theory of evolution, according to which the conscious experience would be preserved because of its adaptive function in the physical world, one sort of phenotype responsible for survival: "[...] they could hardly help us to survive if they do nothing to the physical world." (JACKSON, 2002, p. 277). Jackson disagrees with that view citing the weight of the thick skin of polar bears as an example of phenotype that has no survival value, being the weight of the skin just a side effect of another 
property of the skin, its thickness, which have a function adaptive. The thick skin would have a survival value in the harsh winter, unlike the weight that accompanies it, which, would make the animal slower, jeopardizing their survival, although, in the bear case, the weight disadvantage could be overcame by the gain of heat in survival: "[...] the advantages for survival of having a warm coat outweighed the disadvantages of having a heavy one." Based on this example Jackson concludes, in accordance with his epiphenomenalism, that the experience of pain, as well as other qualia, would be only a "[...] byproduct of certain brain processes that are highly conducive to survival." (JACKSON, 2002, p. 277).

Against this second Jackson's argument, I start considering an example of other qualia, different from the pain. Even accepting that not always and all qualia have an adaptive function, this could not be asserted to all conscious experiences. Could it be claimed, for example, that the visual experience, as such, has no survival value, but only the brain events that instantiate it? If this is the Jackson's thesis, I guess that two points should be considered. First, to what extent brains that have visual experience are different from brains that do not have them. For example, the size of the area of the brain dedicated to the sight would be the same in normal and blind persons? Second, Jackson would believe that visual experience is not adaptive? But this implies that a blind man, or a normal person with his eyes closed, would have the same performance as someone who sees normally. Could the former drive, for example? Going back to the pain. It has no adaptive function? Its existence makes no difference to the physical world? There would be analgesics, dentists, etc., without any experience of pain? This is so counterintuitive and so contrary to the existent knowledge in evolutionary biology and neuroscience that it would be up to Frank Jackson to demonstrate his epiphenomenalist, which, I think, is mainly motivated by his inability to understand how conscious mental events, being a non-physical property of the brain, could act causally on brain physical events. ${ }^{15}$

The third Jackson's argument in favor of epiphenomenal qualia, that is, against the causal role of conscious experience, consists in refuting the idea that we infer the existence or non-existence of minds in beings, similar or

${ }^{15}$ As Frank Jackson himself says: "All right, there is no knockdown refutation of the existence of epiphenomenal qualia. But the fact remains that they are an excrescence. They do nothing, they explain nothing, they serve merely to soothe the intuitions of dualists, and it is left a total mystery how they fit into the world view of science. In short we do not and cannot understand the how and why of them." (JACKSON, 2002, p. 278). 
different from us, because we have established a causal relationship between the conscious mind and certain types of behavior, which would indicate that we assume that the conscious mind is a condition for specific behaviors: "That is why we think that stones do not feel and dogs do feel [...] how can a person's behaviour provide any reason for believing he has qualia like mine, or indeed any qualia at all, unless this behaviour can be regarded as the outcome of the qualia." (JACKSON, 2002, p. 277). Jackson refutes this argument using an example that he recognizes to be limited. The fact that I read in The Times that the Spurs basketball team won is a good reason for me to think that the Spurs really won and that its victory caused The Times' report. We could also think that the Spurs victory also caused a report in The Telegraph, without postulating that the second newspaper report was caused by the first newspaper report, that is, that an effect caused the other; both reports are effect of a common cause, the victory of the Spurs. In what follows Jackson applies the same reasoning to the relationship between brain and behavior, claiming that both, qualia and the behavior, are the result of brain events, that there is no causal relationship between the first ones, as there is no causal relationship between the newspaper reports: "Qualia cause nothing physical but are caused by something physical. Hence the epiphenomenalist can argue from the behaviour of others to the qualia of others by arguing from the behaviour of others back to its causes in the brains of others and out again to their qualia.” (JACKSON, 2002, p. 277).

About this argument, I would like to emphasize that I agree with the thesis that the brain events are the cause of both, qualia and behavior, but it does not mean that the qualia, that is, the conscious mind, do not have a relevant and indispensable causal role for the specific brain organization required to produce specific behaviors. In the same direction of the examples cited above, I propose two other examples to better clarify how I understand the causal role of the conscious mind in the physical world. When someone sees a person recognizing her as an old friend and greeting her warmly, the sight (conscious visual perception), the recognition (conscious memory) and compliance (conscious behavior) result from the activity of her brain, whose structure was forged by previous conscious experiences, that is, the brain that is able to see a person, recognizing her as an old friend using specific gestures and words to greet him, is a brain whose structure was forged by their biological history as much as by its previous history of conscious experiences. Let me give another example. When someone decides to kill a group of people because he believes that in doing so he is acting according to a divine 
plan, it can be inferred that the belief, the decision and action stem from the brain activity, but, again, it might not be forgotten that the brain that carries these beliefs, intentions and capacities to act is a brain whose structure was created by both, its biological and sociocultural history. It is a common sense in neuroscience that brains that have knowledge and cognitive, affective and distinct volitional skills are structurally different, and these differences are not only inherited biologically, they are also built for the physical and sociocultural history after the birth, as shown studies about brain plasticity already mentioned in this paper. In short, the conscious mind is essential for the brain to acquire specific physical structures and features that allow it to undertake the most basic behaviors related to survival and the most abstract and complex behaviors related to sociocultural life.

\section{The Brain is the Agent}

Next I would like to clarify an essential aspect of the double face view on mind-brain relationship. It is about the privilege ascribed to the embodied and situated brain as the agent who takes decisions and implements actions. As I have already said, I think that the conscious mind is a property of the brain, and that the body and the physical and sociocultural environment, although necessary for the existence of the brain and for the most part of the conscious mind contents, also could be considered as contingent. What I mean is that a specific conscious mind could be, as it has been, in different environments and, at least in principle, be in different bodies, but not in a different brain. Let me talk a little bit more about this point.

It is a common sense that whenever a body moves in the environment, its conscious mind accompanies it, being its mental content largely determined by the physical and sociocultural environment in which that body is embedded. I am assuming that a particular conscious mind accompanies its body, although, thanks to its memory and imagination, it could wander in other places and times. So, when one visit a new place, a new city or a new country, his conscious mind accompanies his body, that is, the new content of his conscious mind, new landscapes and people, for example, are those propitiated by the environment in which his body is situated. So, a body is necessary for a conscious mind, the latter accompanying the former, and a particular environment is contingent to a conscious mind, for that could change, in fact, the environment is always changing, although some external 
environment is necessary for the survival of the body and for the content of its conscious mind.

But, to some extent, a body is also contingent to a conscious mind, whereas its brain is not. Let me consider a thought experiment mentioned sometimes to address the issue of personal identity. Let us suppose that brain transplants were feasible and that it was possible to transfer a brain from one to another human body. Being the case, a particular conscious mind would accompany its brain leaving the previous body behind, which could even get another brain and, consequently, another conscious mind. Although a brain requires a body to survive, bodies being then necessary for the existence of brains and, therefore, for the existence of conscious minds, a particular body would be contingent to a brain since it could take another body, being its conscious mind situated where its brain is located. If that brain were transplanted into another body while sleeping, it would wake up in this other body, living a strange situation, maybe believing that it was getting crazy. But its conscious mind would be with it in this new body, living that crazy experience.

As I think that the conscious mind is a property of a brain, and not a non-physical Cartesian substance, I would not be possible, even in principle, go further and exchange brains separately from their conscious minds. If it were possible to make a copy of a body, its conscious mind could, in principle, be carried with its brain to the new body. But, if it were possible to make a copy of a particular brain and its conscious mind, the result would be the creation of a twin. A copy of a brain could have a conscious mind identical to the original brain, but they would be distinct individuals, living, from now on, different experiences.

\section{Final Considerations}

I presented a non-reductive physicalist view of mind-brain relationship, which aims to offer an intelligible interpretation of the notion of mental causation paradigmatically criticized by Jaegwon Kim. The basic idea is that the conscious mind, that is, the set of conscious subjective experiences, is a property of the brain by which the brain interacts causally with the body, and with the physical and sociocultural environment. The structure and functioning of the brain are constructed by genetic program, by the physical/ chemical environment in which the brain is embodied, and by the external 
physical and sociocultural stimuli. The cognitive and affective contents of the conscious mind work as a sort of feedback, a guide that the brain uses to act on the body and on the external world, allowing it to satisfy its biological needs and deal with sociocultural demands.

I am assuming that without the conscious mind, the brain would not be physically what it is, and, by consequence, it would not have constructed what it is related to what it is generally called culture, encompassing arts, science, religion, social life, etc. At the same time, everything that the brain performs is the result of its macrophysical and microphysical structure and functionality, which is in part dependent on the physical and sociocultural stimuli that it captures through its property, the conscious mind. As it was said before, it is through the conscious mind, though not exclusively, that the brain interacts with the body and with the physical and socio-cultural world. Putting the mind-brain relationship in these terms, I am claiming the causal role of the brain and the causal role of the conscious mind, without rendering the latter an immaterial substance independent of the former, and without reducing the latter to the former. I think that to consider the conscious mind as a property of the brain, without which the brain would not be what it is, and would not create what it has being creating, is a way of making the notion of mental causation intelligible.

Remembering what it was said in the introduction of this paper, it was not my priority to argue here for the non-physicality of the mind and for its irreducibility to the brain. Rather, I wanted to check if, from these two assumptions, it was possible to face the criticism of unintelligibility often addressed to the notion of mental causation. So, I proposed a double face view of the mind-brain relationship, assuming that what is already known in Neuroscience allows us to postulate that we are essentially a brain embodied and situated physically and mentally, that the "thing that thinks" is the brain, which would not be physically what it is in every moment of its ontogenetic history, and would not have constructed the sociocultural environment, with which it interacts via its body, if it had not the property conscious mind. So, to accept that the brain interacts with the physical and sociocultural environment through its conscious mind implies that to understand most aspects of human life - health, education, art, science, moral, etc. - it should be considered both faces of the mind-brain relationship, the mind as brain and the brain as mind. 
COELHO, Jonas Gonçalves. Uma abordagem dupla face da relação mente-cérebro: o problema da causação mental. Tans/form/ação, Marília, v. 40, n. 3, p. 197-220, Jul./Set., 2017.

Resumo: Interpretando resultados de estudos neurocientíficos contemporâneos, apresento, em linhas gerais, uma abordagem fisicalista não-reducionista da relaçâo mente-cérebro, a partir da qual a crítica de ininteligibilidade atribuída à noção de causação mental é considerada. Assumindo que uma crítica paradigmática à noção de causação mental é aquela apresentada por Jaegwon Kim, em suas reflexôes sobre a teoria da superveniência mente-corpo, considero criticamente o seu argumento, oferecendo uma concepçáo geral a respeito da relação mente-cérebro, a qual acredito tornar a noção de causação mental inteligível. Penso que o principal problema do argumento de Kim se relaciona à formulação da questão da causação mental por ele aceita. Por exemplo, ao perguntar "como os eventos mentais, sendo propriedades não-físicas do cérebro, podem agir causalmente sobre a estrutura e funcionamento do cérebro?" a mente está sendo considerada não como uma propriedade do cérebro, mas como uma substância cartesiana. Entendo que, em vez de perguntar "como a mente age causalmente sobre o cérebro?", como se a mente fosse algo dele separada e independente, seria mais conforme a uma concepção fisicalista năo-reducionista perguntar "como o cérebro, guiado por sua mente, pode agir causalmente sobre si mesmo?" Para justificar essa formulaçáo do problema da causaçáo mental, proponho uma "abordagem dupla face" da relaçáo mente-cérebro, segundo a qual a consciência é a propriedade essencial da mente, sendo a mente inseparável do cérebro, embora a ele irredutível, e a estrutura e funcionamento do cérebro dependente numa certa medida da existência da mente. Isso significa, em termos gerais, que a mente consciente resulta da estrutura e funcionamento do cérebro "mente consciente como cérebro" -, e que o cérebro, usando a mente consciente como um guia para sua ação, interage com seu corpo e com o ambiente físico e sociocultural circundante, construindo e sendo construído por ambos - "cérebro como mente consciente".

Palavras-Chave: Abordagem dupla face. Mente consciente. Causação mental. Relação mente-cérebro. Superveniência. Jaegwon Kim.

\section{REFERENCES}

BLOCK, N. Consciousness. In: GUTTENPLAN, S. (Ed.) A companion to the philosophy of mind. Malden; Oxford: Blackweell, 1995. p. 210-219.

CHALMERS, D. J. The conscious mind. Oxford: Oxford University Press, 1996.

CHURCHLAND, P. Eliminative materialism and the propositional attitudes. Journal of Philosophy, v. 78, n. 2, p. 67-90, 1981.

CHURCHLAND, P. S. Touching a nerve: the self as brain. New York: W.W. Norton \& Company, 2013.

CRAINE, T. The significance of emergence. In: LOEWER, B.; GILLETT, G. (Ed.). Physicalism and its discontents. Cambridge: Cambridge University Press, 2001. p. 207-224.

DESCARTES, R. Les principes de la philosophie. In: Oeuvres et lettres. Paris: Gallimard, 1952. 
GAZZANIGA, M. S. Who's in charge: Free Will and the science of the Brain. New York, Harper Collins, 2011.

JACKSON, F. Epiphenomenal qualia. In: CHALMERS, J. D. (Ed.) Philosophy of mind: classical and contemporary readings. New York; Oxford: Oxford University Press, 2002. KIM, J. Mind in a physical world: an essay on the mind-body problem and mental causation. Cambridge: MIT Press, 1998.

LeDOUX, J. Synaptic self: how our brains become who we are. New York: Penguin Books, 2002.

NAGEL, T. What is it like to be a bat? In: GENDLER, T. S.; SIEGEL, S.; CAHN, S. M. (Ed.). The elements of philosophy. New York; Oxford: Oxford University Press, 2008.

PLACE, U. T. Is consciousness a brain process? British Journal of Psychology, v. 47, n. 1, p. 44-50, 1956.

RYLE, G. The concept of mind. London: Hutchinson, 1949.

SALE, A.; BERARDI, N.; MAFFEI, L. Environment and brain plasticity: towards an endogenous pharmacotherapy. Physiol Rev., v. 94, n. 1, p. 189-234, 2014.

SEARLE, J. The rediscovery of the mind. Cambridge: MIT Press, 1992.

SKINNER, B.F. About behaviorism. New York: Vintage Books Edition, 1976.

SMART, J. J. C. Sensations and brain processes. Philosophyical Review, v. 68, n. 2, p. 141$156,1959$.

Recebido em 04/07/2016

Aceito em 11/02/2017 